\title{
New! Post: Two Sets of Four Brick Buildings
}

\author{
KEVIN HIRTH \\ University of Colorado Denver
}

\section{NOT NEW}

"New! Post" asserts the premise that by studying the detailed use of a single material, a deeper understanding of the connections between built works of architecture can be evaluated. In this case, the use of brick serves as a polemically appropriate vehicle for the contextualization of architectural practice at present into clear discussion with a tectonic tradition of the past. Brick masonry is an appropriate starting point for cross-referencing current architectural practice against the references that preceded it because of its inherent limitations. It is a material that has a deep history and a narrow latitude for application. This paper uses a comparative method to understand the alignment between the modes of practice today with the late-modern period commencing at the close of the 1960s. The parallels between these two periods, and the influence of the one upon the next, is instructive for understanding the nature of architectural discourse today. While architecture, like any creative pursuit, is always positioned to respond to the immediate present and past in a critical manner, the architecture of the present is in a particular phase of reactivity. By establishing the critical lineage of the present to several instances of architecture of the late 1960's, a trend emerges that allows us the opportunity to project forwards.

Precedent and language are the currency with which a building gains value as architecture. Architects seeking to contextualize their work within their discipline are faced with adopting a language that has been established for several centuries. Likewise, they often use their predecessors to situate a project in a landscape of similar important buildings. This notion of translation and relation enables the architect to aggrandize and justify. This has been a necessary truth since the writings of Vitruvius and the drawings of Palladio. Architecture is inherently backwards looking, even when striving to innovate and make new. When Gropius famously removed all evidence of classical ornament and entablature from the architecture school at Harvard upon his arrival, his negation still qualified the work of his students in relation to this missing history as a foil. In accepting the role of history and a common language of description within architecture, the discipline builds on the shoulders of the past. This cannot happen progressively, however, without a healthy portion of irreverence. The lasting lesson of the ultimate failure of high postmodernism was that it came to take itself too seriously. At its prime, and as it has recently reemerged today, it is playful and improper. This dexterity accepts the elasticity of history and undermines the unilateral nature of a common language of description. That contemporary practice is reopening this approach speaks to the failure of traditional forms and tropes. The twenty-first century is, in short, no longer easily describable through a pre-millennium lens. The complexities of interrelation at a practice-to-practice or even project-to-project level have rendered the bucolic notion of an overriding architectural movement completely obsolete. Just as the Sears catalogue gave way to our present's complex and ever-expanding marketplaces, the traditional conception of architecture as a unifying cultural gesture has given way to a diverse and individuated free system.

To accept the elimination of categorical unification in contemporary practice is to declare our present as a patchwork quilt of laterally connected but unconcerned collectivity. Practices relate to one another, even imitate one another, but do so knowing that such reproduction is an acknowledgment of difference rather than of similarity. This siloing of individuality requires that practices create their own ground upon which to grow. Each practice must theorize, relate, invent, and communicate for itself. This exercise in self-support finds its roots in the dissolution of high modernism in the late 1960's. This, a period in which progressive architecture was largely questioning the future of high modernism and its expansion into pervasive global practice, saw a number of practices formulate a conceptual territory as separate from the herd mentality of the rapidly corporatizing movement.

\section{NOT OLD}

For the sake of indexicality, consider four brick buildings constructed within a three-year period of one another that individually marked both a response to the contemporaneous pervasive building culture and a declaration of individual conceptual territory. In 1969 Louis Kahn finished his seminal meditation on the brick, the Exeter Library. In 1968 Kallman McKinnell \& Wood completed construction on their byzantine Boston City Hall. In 1968 Robert Venturi dedicated his Columbus Indiana Fire Station. In 1966 Alvar Aalto opened the Auditorium at the Helsinki Technical University. Four buildings constructed using brick. Four buildings otherwise entirely disconnected from one another in disciplinary context. Peers in their establishment within the canon of architecture, these four buildings from the height of the post-war period are identified singularly as separate from one another. Beyond being four contemporaneous works primarily characterized for their use of brick, there is little written to connect the buildings as 


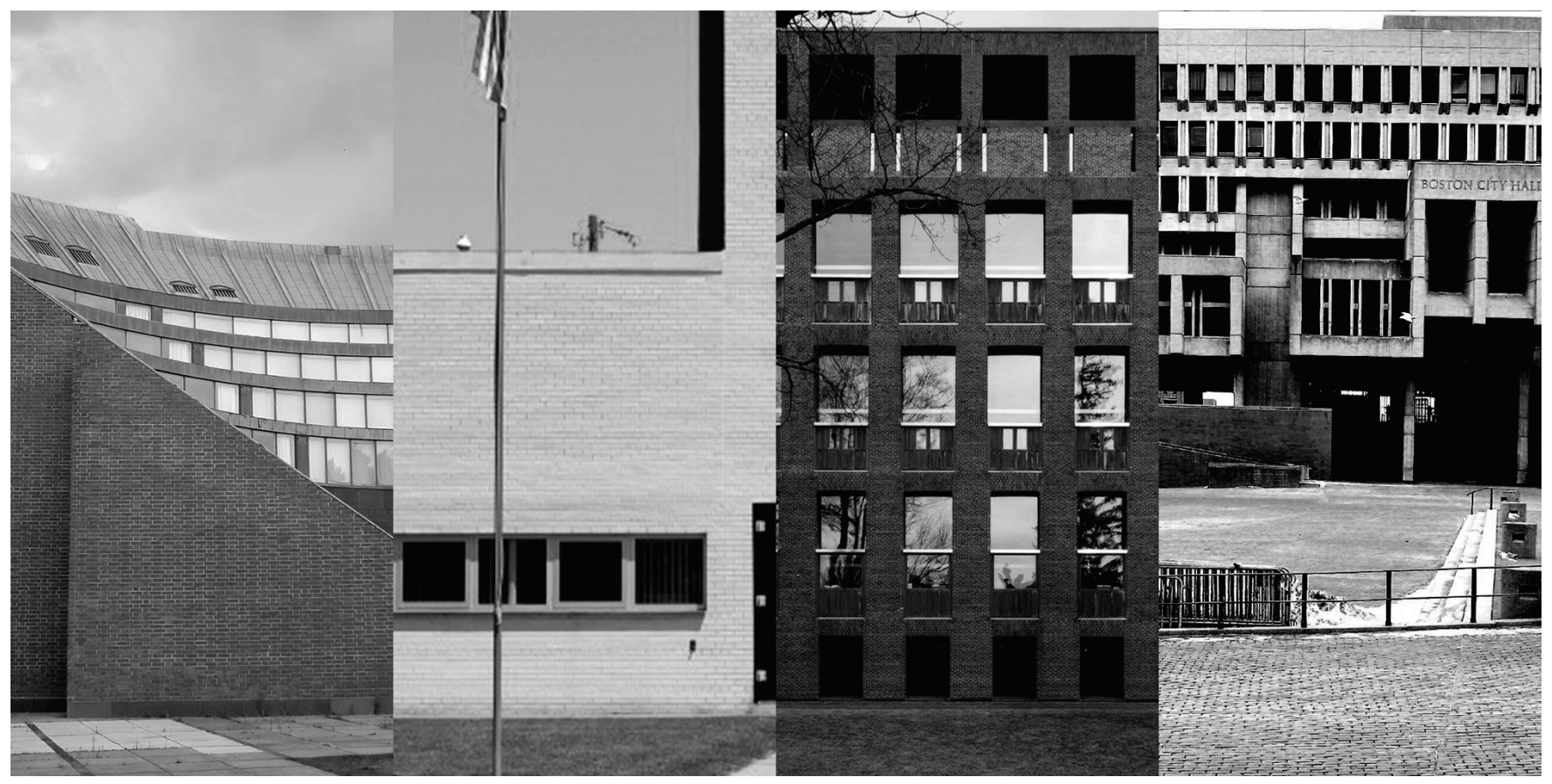

Figure 1. Aalto, Ventui, Kahn, KM\&W.

disciplinarily native to one another. These buildings are, nonetheless, statements on the close of high modernism and the rise of a period of late and post-modern hand wringing. Each work makes its own statement on the status of modernism as a unifying social, political, and aesthetic movement. Each work likewise exists in complete isolation from the next. These four brick buildings form the seam between two identifiable periods of architecture, providing our present discipline with a lesson on contextualizing work in relation to a present that resists clear contextualization.

In the case of Kahn's library, the reliance on monumentality via monolithic scale and repetition is built up in the facade, which seems at first to be relatively normative. On closer examination, the details reveal a subversion of implied uniformity. The windows, growing larger at each level up the exterior, create the appearance of tapered trabeated columns flanking them. The effect is similar to that of a repeating flattened chimney. The domestic chimney shows up again in the dining hall next door, which Kahn constructed under the same commission. In the case of the dining hall "chimney," it is a monolith that marks a single door which inexplicably enters at its base. Kahn is happy to co-opt modern form, but not at the cost of his own parochial Pennsylvanian approach to scale and inhabitation. The building has as much in common with a piece of Shaker furniture as it does with his contemporaries. What ultimately lifts the building into commentary with modernism is Kahn's use of brick, particularly at the four corners of the building. Kahn removes the points at which the four corners would presumably meet in a cube and floats the walls off of one another and off of the building enclosure. Kahn uses the plane to promote a sense of evacuation. The building, like many of Kahn's works in brick, plays with the common visual memory of a warehouse abandoned and evacuated of life. Kahn uses the tools of his own context to generate a haunting sense of nostalgia for the domestic and deteriorated austerity of post-industrial modernism.

Venturi's Fire Station uses a similar countenance of American vernacular but draws it out of a place of optimistic co-option. The Fire station is a comingled collage of symbols placed in composition to telegraph typology. The residential square window complete with crossing muntons, the ribbon window of Le Corbusier's early modernism, the parapet wall lifted artificially to imply a billboard, the tower with signage, the flagpole placed off-center. Everything is in place to telegraph the expected visual symbols of a fire station, yet placed out of scale or position. Venturi's use of brick, however, is his most deliberate swipe at modernism. Venturi uses two different colors of brick on the facade, dividing the composition into three parts. The white brick creates a figure over the building that appears to cover or overlay the red brick, yet is flat and divided with a $1 / 2$ inch masonry expansion joint. The division of the facade into these two contiguous parts is at direct odds with Kahn's notion of material authenticity. The brick is allowed to take on a graphic quality. This graphic flatness heightens the reading of the front facade as a distinct plane projected in two dimensions. Venturi seeks to flatten the reading of the building into a single image, denying the plasticity and supposed dynamism of modernism's preference for the oblique. 
In the case of Kallman McKinnell Wood's Boston City Hall, the brick is not perhaps the first material that one calls to mind from memory. The building itself is undoubtedly a landmark use of cast-in-place concrete. The building, however, is only one half of the proposition put forward by $\mathrm{KM} \& \mathrm{~W}$. It springs from a massive brick plaza that was carved out of the dense city center to create public space. A hallmark monument of Urban Renewal, several city blocks of high-density low-rise brick buildings were demolished to make way for the plaza and hall. The plaza, in a nod to contextuality, was cast in brick. Like a pool of syrup on a stack of pancakes, the plaza covers every surface of the site and seems to spread up the sides of the Hall itself. Out of this massive expanse, the concrete of the projecting and overhanging city hall building is meant to appear light and effortless. Kallman and McKinnell, who devised this competition winning design while still students in graduate school, were carrying the prevailing tone of modernism to it's logical extreme. Unbounded, the building and plaza obliterate the scale of the city. The landscape's reduction to a single material motif with little articulation is meant to heighten the registration of the articulation of the building facade. This is a version of extreme modernism that, while deemed brutalist by the popular reckoning, is perhaps better positioned as an adjacent neighbor to Le Corbusier's imagining of public space in his Plan Voisin. Extreme in proposition, oppressive in reality.

Lastly, consider Aalto's auditorium for Helsinki Technical University. Aalto's use of brick in the building is surprising considering his extensive use of the material as a finely crafted and tooled material. In the auditorium, Aalto uses the brick in a brutish manner. It is applied as rudimentarily as possible, installed to appear as a simple solid mass. Unlike his earlier Muuratsalo Experimental House, in which he pursued a wide array of uses of the brick as a primary element, Aalto is pouring the brick over the form uniformly to set up its apparent solidity. By using brick at and around the entire perimeter as a solid unbroken material, the auditorium slope is set up as an undeniable interior that has been carved out. Aalto is using the materials to imply some past state in which the building was upright and has been excavated at an oblique. The carved face, rendered in copper and glazing, is a luminous and hearty shade of green set against the unperturbed hue of the mass itself. Aalto's work is a bridge for bringing the fetish of material surface effects from the arts and crafts movement of the early twentieth century into the late modern period. The auditorium shows that he as often used the machinic uniformity of industrialized construction to further the effects of material weathering as he did the fine crafts of his thendying generation. Here, Aalto acknowledges the effects of modernism on construction in his time, and comments on it by capping and finishing it with a more hand-hewn edge. This selective craftiness would become a hallmark of late postmodern romantic work like that produced by firms such as Todd Williams Billie Tsien.

\section{NOT MANNERED}

These first four brick buildings demonstrate the legacy of a generation that was caught up in a sweeping unifying aesthetic movement and forced to respond to it in some way. These buildings were also able to comment on the clear registration of the changes apparent in their time. Where there was a black and white dichotomy to register against, the buildings of our present are pressed to relate to a steady unrelenting gray. It has been twenty-two years since the last MOMA exhibit attempted to situate contemporary practices together in an attempt to formulate some reference to a coherent architectural movement in Terrance Riley's "Light Construction." Twenty-two years have reshaped practice beyond recognition and seen the side characters of this exhibit emerge as international forces. Since this time, the beneficiaries of Neo-Liberalism have spread individuated buildings across the globe wielding astonishing resources to construct works that seek to define an otherness of branded individuality. Self-aware and unselfconscious, architecture has become individuated to a point of absurdity. Architects have wielded the tropes of their own practice to mold a recognizable brand, which is in turn imitated poorly by larger and better funded corporate practices ad nauseum. This insistence towards polyamorous individuation has left students and junior practices in the profession with little of coherence to respond to. New work tends towards imitation and searches for trends rather than a discourse around any manner of social, ethical, philosophical, or historical issues. With no movement to assail outside of the cult of individual personalities, it has become the task of the polemical practice to work in the margins and mine clever associations.

It has also become critical for practices to band together into association with one another. Take as a proof the recently published indexical monograph "Possible Mediums" by Kristy Bailliet, Kelly Bair, Adam Fure, and Kyle Miller or the critical essays found in "Not Interesting: On the limits of Criticism in Architecture" by Andrew Atwood. Both books operate under the premise that the language of architecture that was inherited from previous generations of architects is no longer suitable to contemporary practice. The books both put forward that individual work is self-derivative of new languages that help to define the work. The effect is simultaneously liberating for its severance from convention, while conveying that there is a crop of architects coming who operate by their own as-yet established systems of values and assessment. There is little to unify the practices that these books pull together beyond their mutual interest in crafting a new work while appearing to state something obvious but never rightly understood previously.

Consider then that the lens of common assessment for our four brick buildings from 1969 was that of the pervasive and encompassing language of the modern movement. Once we accept that we are in a period in which the language to 




Figure 2. Atlas Huis, Monadnock.

describe architecture is open, we must devise a new means to assess today's architecture through a comparative lens that is far more complex in nature than that offered by our 1969 four. If architecture is standing by tradition and continuing to respond to a common language and foundation, then it bears the need to isolate the traits and tropes of our present. Our contemporary practices have no common language, and therefore seem to speak in a garbled mixture of reference, syntax, image, and elemental trope. Through comparison, however, a common understanding of the collective enterprise becomes apparent.

Whereby the 1969 four were responding to high modernism, the 2019 four are evidently responding to the dissolution of coherence that has given way to brand-individuation at the discipline's higher levels. Much like the 1969 four, the works of the present wield architectural reference not in the mannered tradition of previous periods, or in the symbolic patterning of high postmodernism, but rather as an opportunistic search for familial form. As Giovanna Borasi noted in her introduction to the recent CCA catalogue of the exhibition Besides History: Go Hasegawa, Kersten Geers, David Van Severen:

"Far from a postmodern position that evoked historical architectural forms literally, and far from the work of the previous generation that used history to create a new theoretical foundation for architecture or to return to a modern position that negates the importance of history--when architecture tried to free itself from the weight of the past, developing new values and a language very much reliant on the trust in the future and the promise of technology-- history becomes here, in the conversation between OFFICE and Hasegawa, a constellation of references selected from many historical periods and geographies...that reveals a very different attitude of inquiry, more directly related to the architects' aesthetic research and approach without becoming strictly operational or literal."

Borasi's observation on the conversation between Go Hasegawa and OFFICE can be extended to begin to relate a larger conversation in contemporary practice. For this exercise, consider the following four brick buildings, each put forward by offices in the nascent stages of their establishment.

\section{NOT LITERAL}

First examine Altas Huis by Monadnock Architects. The building, which clearly owes a Venturian legacy, uses brick as a flattening material that carries mass and transmits a stable surface quality. There is, however, a subtle difference. In Venturi's work in brick, he makes a strong effort to differentiate changes in material tectonically. In the case of Monadnock's house, the use of differentiation of color is applied cheaply and deliberately with a layer of paint wrapping portions of the outside surface of the building. In this, the house has more in common with Edward Lutyen's Grosvenor Estate, where the brick is covered with plaster in a relentlessly graphic checkerboard of texture. Monadnock also uses a rough mason's hand in the application of mortar 


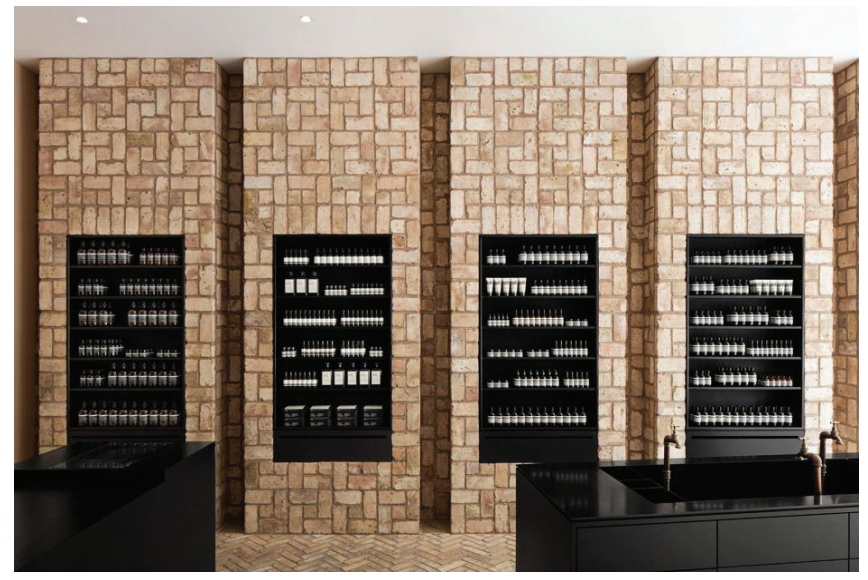

Figure 3. Aesop Bucktown, Norman Kelley.

and brick. The brick remains unscoured and roughly applied. The hyper-relief of the rough brick mortar transmits clearly through the whitewashed paint. Through a simple detail, at the openings Monadnock leaves the paint only on the outward facing surface and uses a simple brick lintel. The result is an articulation of the brick showing only on it's short face around the opening. This articulation of texture at the window opening hearkens crudely to Adler \& Sullivan's Carson Pirie Scott building, where the evident face of the building is left relatively blank, but the surfaces of the window opening are finely tooled. The placement of openings and the introduction of a small square or pixelated dot motif to the facade takes a playful figural quality. The pseudo-anthropomorphic effect, not unlike the entry facade of Gordon Wu Hall at Princeton University by Venturi Scott-Brown, has a gravitational effect of it's own. Neither asymmetrical nor symmetrical, the composition is reliant of an occupation of the corners. Unlike the modern device of the open floating corner as formally proselytized in Walter Gropius's Bauhaus Building, Monadnock draws out the mass of the corner and places windows into close proximity. The unlike sizing and adjacency of doors and windows at the corners gives a notion of openness and order disrupted. To round out the reading of the building as a solid mass, the cornice line of the house is tapered at a subtle radius in elevation. Monadnock uses the same trick that we find in Aalto's auditorium. By cutting the primary mass of the solid in an unexpected manner, the solidity of the building is reinforced. This effect is doubled by maintaining a datum for the native brick color and texture at the top of the first floor. This creates a flat and artificial reading of a podium and pediment. The result of these coalescing self-conscious references is a building that derives it's complexity and uniqueness from its development of these varying and overlapping influences into a coherent whole.

We find a similar approach is evident when taking a closer look at Norman Kelley's interior remodel of a storefront for the Aesop company in Bucktown, Chicago, Illinois. The project, strengthened by reading it as an integrative extension of the existing building, presents several anachronistic responses to its context and use of material. The brick interior is situated inside a brick shell. The new interior brick walls and floor are floated on pedestals, artificially suspended. Norman Kelley chose a contrasting brick to the exterior to deliberately distinguish it from the old. This device, though, is more clearly relative to a work such as the Piazza del Campo in Siena, where the material is used to connote significance rather than newness. Like the Boston City Hall plaza and building, this points towards a contradictory reliance between the two parts. The built-out interior seems to hold up the building as much as the building seems to house the interior. This implication is reminiscent of MVDRV's recent Crystal House for Chanel in Amsterdam, albeit via far subtler (and less tortuous) means. Stepping into the interior itself, the use of brick is evidently deeper in nature than the existing shell around it. The conflicting patterns of herringbone brick for the floor and the pinwheel of the walls sets up an immediate acknowledgment of intersecting pattern. The walls, which step in and out to house various displays, cleverly use the pattern to turn each corner seamlessly. The resultant effect is that the brick is doing somersaults in the wall cavity in order to convey a flatness and superficiality on the surface. The brick-aswallpaper approach is an intelligent an surprisingly un-fussy extrapolation on buildings such as Mario Botta's Lutzoplatz apartments, where we see the pattern of the brick fetishized into an optical machine. Norman Kelly is careful, however, to not be too slick about their work. Their interior is set up as an antithetical proposition to the endless fluidity of other contemporary buildings, such as Mecanoo's Bolling Building in Boston, where the turning tectonic pattern of the brick is made continuous and blended into a single surface that attempts to manage varying complexities. Norman Kelley's interior is the anti-single-surface building, representing instead a reinvestigation of the individual room with separate distinct parts. Chair rail, wainscot, window, door, casework, counter, and sink each conceived as an integrative part of a larger whole. This, surprisingly, is representative of a somewhat radical approach to a contained piece of architecture that is a clear break from the slicked down corporate work of the hegemonic popular elite.

Take now the Mother-In-Law's House by my own office, Kevin Hirth Co., in Denver, Colorado. The guest house, which sits in the middle of a block behind a principal dwelling, is an inhabitable brick column. The building deforms from a circular base to a rectilinear top. This eccentric geometry allows for the tectonics of the corners of the building to zipper rather than meet at a squared corner. This simple premise, when extrapolated, results in a structure with similar hollow features as Kahn's Exeter Library, but with a more singular and mundane expression upon its whole. The building attempts to combine the rich textural qualities of the zippered brick, but simultaneously mutes the tower into a platonic singularity that calls to mind Rossi's Fagnano Olona. This playful exposition of the 


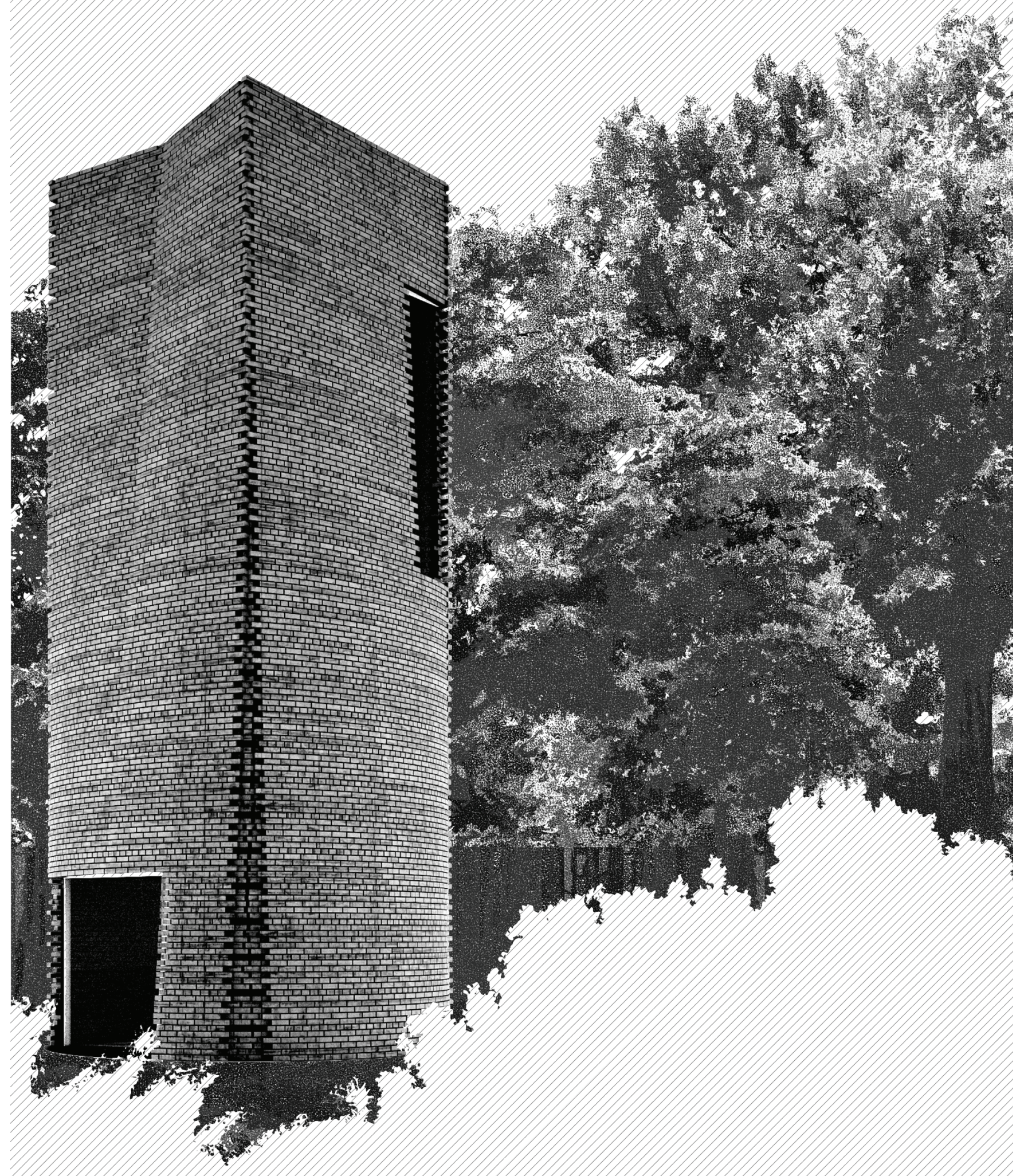

Figure 4. Mother-In-Law's House, KEVIN HIRTH Co. 


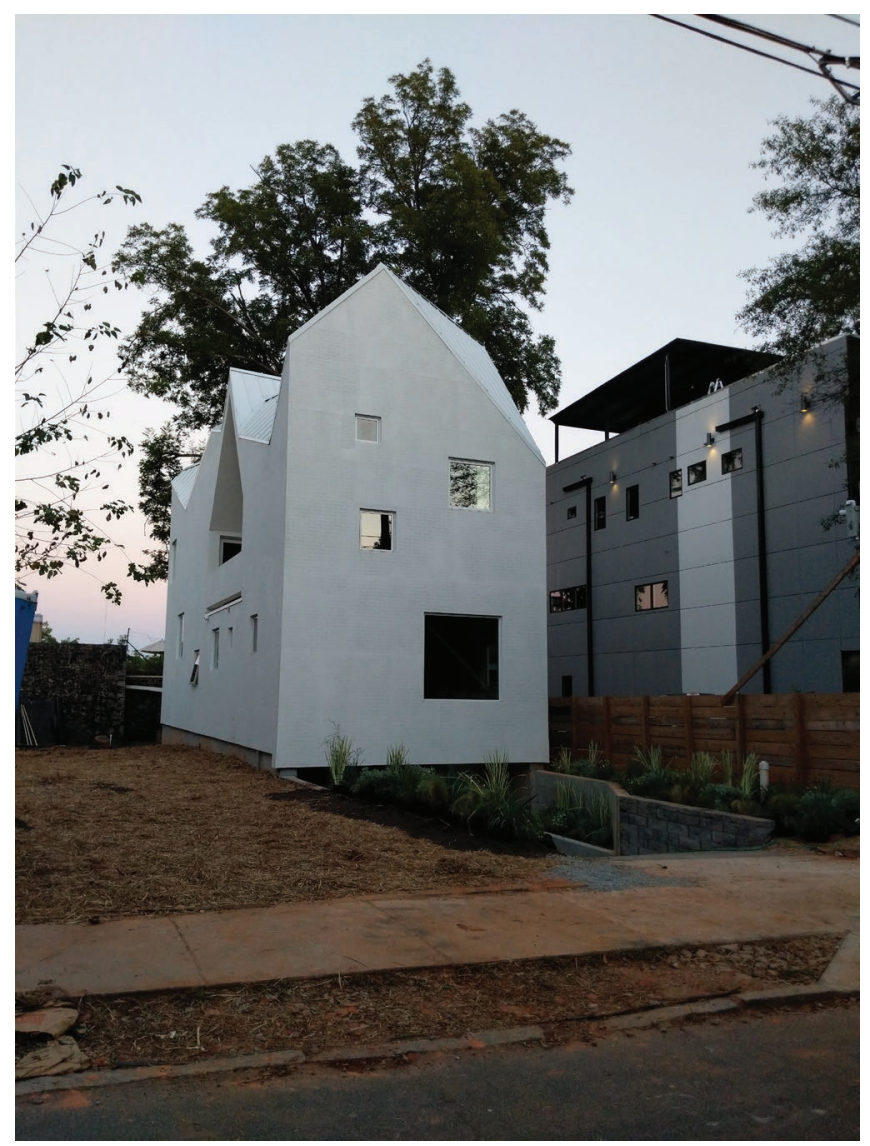

Figure 5. Haus Gables, MALL.

zippered brick takes evident homage from Office DA's Casa la Roca and Herzog \& DeMeuron's Tate Modern Extension. Where it differs, however, is its insistent subtlety of this effect. The building more closely resembles a smokestack in a state of deterioration than a marvel of techno-craft. The unfinished edges of the brick where it meets openings hearkens to H.H. Richardon's Sever Hall, where every opening and corner is carved and articulated to connote a fineness of detail. Yet, again, the house is distinct in generating this effect through a simple means. The corners simply remain incomplete. The diminution of the building is at odds with its monumentality. The building has a fictional quality to it, yet it does not use that truth to generate some outsized achievement. Its strength is its false modesty, projected by representation in drawn form. The building, a tower in miniature, is perhaps its most radical for its diminutive stature. It uses the monolithic quality of the unbroken masonry wall to imply a grandeur that it intentionally falls well short of achieving.

Lastly, consider Haus Gables by Jennifer Bonner's MALL. The house, currently under construction in Georgia, is not a brick house at all. The building is constructed using crosslaminated timber and clad in a custom brick-stamped stucco. Presenting itself as a not very convincing faux-brick building, the house confronts the authenticity and artificiality of brick as a legitimate building material in contemporary construction. Very rarely used as a load-bearing material, the brick acts as a veneer in its contemporary usage. Given its weight and poor performance as a veneer material, the brick's use as such makes little sense beyond an aesthetic one. In this sense, Bonner's project is reminiscent of James Wines' BEST stores built across North America in the 1970's and 1980's. Conceived as billboards of the impermanence of consumer culture in a post-capitalist society, the BEST stores are evaluative in their keen social observations. They treat the expression of the brick as something false, and then tease us into imagining it is real. Bonner's house asks similar questions, but also relishes in a clever optical effect that renders the brick both real and faux. A similar effect can be seen in Michael Graves' Martell College on Rice University's campus, where the brick is blown up to the mega-scale as a visual pastiche. At its heart, Haus Gables feels closest akin to the building scale graphic works of Barbara Stauffacher Soloman at Sea Ranch in California, unafraid to conflate material with graphic artifice. MALL makes use of the brick as a false visual pattern and does so in an outspoken way. This is indicative of the opportunistic skepticism of today's upcoming generation of designers. The projection of meaning and intent to counterattack the prolific salesmanship and branding of the prior generation of architects is a return to modes and methods seen by architects in the very late modern moment.

\section{NOT ALONE}

The complexity of the interweaving references, geometries, tectonics, and combinatory languages of these four brick buildings is indicative of the spiraling madness of the early twenty-first century in architecture. With no firm movement or syntax to respond to, these young practices are searching for a language and history of their own. The direction that they have taken indicates a hunger for generating collectivity through pervasive reimagining of the language of architecture. They are collapsing and recombining its expected elements into unexpected new configurations. A study of these four buildings reveals four separate narratives that point towards an open and fearless reappraisal of architectural history. Not quite "post-modern," but rather relentlessly combinatory and increasingly clever. Compared to the much clearer moment of searching evident in the late 1960s, today's practice seen through the lens of these four brick buildings is revealed to be an opportunistic, optimistic, absorption of past conflicting architectures with an eye towards a future yet-unfound collectivity. Similar to the 1969 four, the 2019 brick buildings take a reactive stance that intends to push practice into new territory away from the established trajectory of traditional practice. 